\title{
A Study on Platform Construction of Automobile Industrial Innovation
}

\author{
Qiao Quan-ying \\ Management School, Wuhan University of Technology, P.R.China, 430070 \\ Email: q13903740963@163.com
}

\begin{abstract}
The fulfillments of automobile industrial innovation practices confirm that automobile industrial innovation platform plays more and more important roles. This paper studies connotation, structure and construction of automobile industrial innovation platform. An automobile industrial innovation platform may be dividend into three layers of public platform, automobile industrial platform and enterprise platform. Each layer of an automobile industrial innovation platform consists of three sub-platforms of management platform, technology platform and information platform. The demonstrative analysis of the case of partnership for new generation automobile verifies the accuracy of our study.
\end{abstract}

Key words-Automobile Industrial Innovation Platform, Public platform, Partnership for New Generation Automobile

\section{INTRODUCTION}

With the fast development of science and technology, the time interval becomes more and more short between discovery of scientific knowledge and technological innovation, shown in tab.1. The economic globalization makes the product updating more and more quick. Under the historical period, automobile industrial innovation plays an important role in the development of economy and industry in a country or an area. With the exploration of automobile industrial technology getting more and more complicated, the investment in innovation becomes more and bigger, so it is very difficult for one or a few enterprises to undertake automobile industrial innovation activities. In developed countries automobile industrial innovation platform are usually established to share talents, technology, equipments and financial resources to achieve breakthrough of $R \& D$ activities. It is an important effective way to upgrade the competition capability and improve industry development level of a country or a region.

TABLE 1. COMPARING OF HOUR INTERVAL BETWEEN SCIENCE DISCOVERY AND TECHNOLOGY INNOVATION

\begin{tabular}{lclcc}
\hline Science discovery & Year & Technology innovation & Year & Interval \\
The principle of photograph & 1782 & Camera & 1838 & 56 years \\
Electrical engineering principle & 1831 & Electric generator & 1872 & 41 years \\
$\begin{array}{l}\text { I.C. engine principle } \\
\text { The principle of electromagnetic }\end{array}$ & 1862 & Gasoline I.C. engine & 1883 & 21 years \\
wave communication & 1895 & Public broadcasting station & 1921 & 26 years \\
The principle of radar & & & & \\
The discovery of semi-conductor & 1925 & Radar & 1935 & 10 years \\
Speculation of integrated circuit & 1948 & Semi-conductor radio & 1954 & 6 years \\
Fiber-optic telecommunication & 1952 & Integrated circuit piece & 1959 & 7 years \\
Speculation of multimedia & 1966 & Fiber-optic electric cable & 1970 & 4 years \\
\hline
\end{tabular}

Although automobile industrial innovation platform is important and practical, most studies are concentrated on demonstration analyses; the theory on its connotation, construction and operation is not mature. It's necessary to research the connotation, structure and construction of automobile industrial innovation platform.

\section{THE CONNOTATION AND STRUCTURE OF}

\section{AUTOMOBILE INDUSTRIAL INNOVATION PLATFORM}

Platform was known at first as an engineering concept which can be traced back to the work 《Modern Man》 written by Henry · Ford at the beginning of the 20th century, where the concept of platform was used to describe the subsystems of auto. After 1980's enterprises such as KODAK, SONY, INTEL and so on began to use the method of platform in the process of new products development. The success of platform in practice attracted the concern of the theory field in management. As a represent, Professor Meyer of the Northwest University (USA) put forward the concept of "Product Platform" and "Technology Platform". Actually, product platform, technology platform and management platform of an enterprise construct its product innovation platform.

Industrial innovation is a combinative innovation of 
technological innovation and institutional innovation. To implement an automobile industrial innovation activity, government, enterprises, universities, institutes and so on must cooperate with each other. By combining with government and social organizations, enterprises' product innovation platforms expand to be an automobile industrial innovation platform. As any single enterprise is impossible to fulfill a complex automobile industrial innovation project, its necessary to establish an automobile industrial innovation platform to integrate innovation abilities scattered in single organization and create powerful innovation ability. The target of automobile industrial innovation platform is for fulfilling complex R\&D activities, especially in pre-competition fields.

The structure of automobile industrial innovation platform includes elements, structure, sub-platforms and so on.

(1) Elements. An automobile industrial innovation project is usually a big, systematic engineering; its elements are government, enterprises and social organizations. Government plays key role in the formation and operation of automobile industrial innovation platform effectively. As the manager of a country or an area, a government can make up market defect and decrease exterior negative effects. They construct high-efficient automobile industrial innovation platform through laying out its object, optimizing the environment, evaluating and supervising, guidance and service, etc. Enterprises are the basic structure element of direct carriers of automobile industrial innovation activities. They are the structure element of development, investment, output and profit. They're core members of automobile industrial innovation platform. Generally, enterprises mainly devote themselves to product innovation and technology innovation. Some important technology innovation items need the participation and cooperation of social organizations such as colleges, research institutes and medium organizations, etc.

(2) Structure. According to the different function that the elements take, an automobile industrial innovation platform may be dividend into three layers: public platform, automobile industrial platform and enterprise platform. Under the guidance of government, a public platform in IIS should be established to reduce innovation risk, undertake investment together, and share resources, etc. Public platform is supported by policy and government's particular investment, and integrates innovation resources of the relevant departments of the government. An automobile industrial innovation project needs an organization to moderate objects and resources of government, enterprises and social organizations. Usually an automobile industrial association undertakes this role. The special standing makes it possible for an automobile industrial association to communicate and integrate resources from government, industry and social organizations. Thus automobile industrial platform is formed. Enterprise platform is the product innovation platform of an enterprise that takes part in the automobile industrial innovation platform.

(3) Sub-platforms. Each of the three layers of an automobile industrial innovation platform consists of three sub-platforms: management platform, technology platform and information platform. The sub-platforms have their own particular functions and characteristics. (1) Management platform. Management platform consists of the senior managers of the innovation platform who take part in the automobile industrial innovation activities. It establishes a highly integrated interface and builds the atmosphere of close contact. It is constituted by various management functions, management methods and management behaviors. (2) Technology platform. Technology platform consists of technology talents, technology resources and technology innovation abilities. The technology platform includes technology principle, designing method, manufacturing craft and crucial equipment, etc. The outstanding feature of automobile industrial innovation is that it integrates many kinds of scientific technologies and different kinds of designing ways. Technology platform is the direct undertaker of technology innovation activities. (3) Information platform. As the elements of an automobile industrial innovation project are very complex, setting up information platform is indispensable so that information can be communicated fluently, shared and transformed efficiently. Information platform is the supporting system and working platform of an automobile industrial innovation platform.

\section{THE CONSTRUCTION OF AUTOMOBILE INDUSTRIAL INNOVATION PLATFORM}

Principles of establishing automobile industrial innovation platform include four aspects. (1) Strategic object directing direction. Industrial innovation activities are not only influence the development of enterprises, but also influence the development and security of a nation. The construction of automobile industrial innovation platform will also influence the development of related industries deeply and far. The object of a nation's development strategy should guide the construction of automobile industrial innovation platform. (2) Plan mechanism combining with market mechanism. As automobile industrial innovation resources are scattering in different social organizations, government's scheduling, organizing and moderating is necessary in integrating innovation resources and form an organic innovation organization. At the same time, competition mechanism should be introduced so that excellent resources can be integrated and superiority repairs with each other. (3) Guiding by government combining with enterprises' corpus standing. The ultimate object of automobile industrial innovation is to exploit product that can meet market requirement. Hence enterprises are the corpus of an automobile industrial innovation platform. But the diversification of enterprises' objects and the complexity of innovation environment determine that government's guidance and organizing is indispensable. (4) Social benefit combining with economy benefit principle. The object of establishing automobile industrial innovation platform is not only considering about creating economy benefit, but also paying attention to social benefit such as industry's international competition ability, employment, environment protection, etc.

An automobile industrial innovation platform is established for particular object. When it has realized its object, it may disappear or update to be a new platform. The updating mechanism of automobile industrial innovation 
platform is shown in Fig.1.

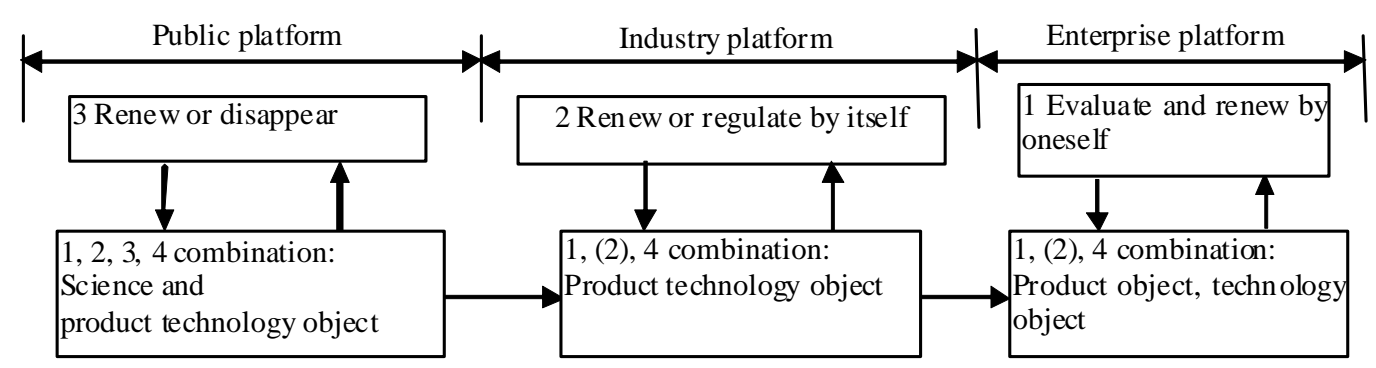

Fig 1. Object and its updating mechanism of automobile industrial innovation platform

Note: The numbers in the figure refer to different elements. ' 1 ' refers to enterprises, '2' refers to automobile industrial association, ' 3 ' refers to government, and ' 4 ' refers to other social organizations.

A public platform is established according to the innovation object of a nation. If the public platform has fulfilled its mission, it will disappear or renew its object, and update to a new platform. After public platform has been established, industry platform will be constructed under the organizing and moderating of automobile industrial association. Generally an automobile industrial association exists for a long time, but the automobile industrial platform establishes for particular object and will disappear or renew after its object have achieved. An enterprise platform establishes and updates according to the core enterprise's development strategy of an automobile industrial strategic alliance.

\section{CASE STUDY ON INDUSTRIAL INNOVATION PLATFORM - THE PARTNERSHIP FOR NEW GENERATION AUTOMOBILE}

In 1980s, Japanese attacked American industry heavily. After a series of investigations, the American government found that it still had advantages in science and technology innovation, although Japanese had great competitive advantages in some industry technology. The American government decided to create a cooperative innovation environment to promote the breakthrough of some strategy industries. Take automobile industry as an example. At the moment of modern auto industry facing with technology breakthrough, in order to keep and upgrade auto industry's international competition ability, the American government launched a huge industrial innovation project that was called partnership for new generation automobile. As a 10-year project, partnership for new generation automobile started in 1993 with an object to develop an $80 \mathrm{mpg}$ (gasoline equivalent) sedan without sacrificing size, comfort, range, and speed. The government spent $\$ 814$ million for partnership for new generation automobile while the three biggest enterprises (General Motors, Ford, and Daimler-Chrysler) spent over $\$ 980$ million. There are more than ten government departments who took part in the project, such as the Energy Resources Department, the Department of Defense and State Aviation Bureau, etc. There are more than 700 government departments, enterprises, colleges, nation laboratories, social research organizations and so on took part in the project. All these resources were integrated to build a large industrial innovation platform of auto industry.

( 1 ) The Public platform of partnership for new generation automobile. The public platform of partnership for new generation automobile is organized by the government to integrate resources and capabilities from different fields. It helped to support the breakthrough of fundamental technology and complex products. (1) Management platform. President Clinton initiated partnership for new generation automobile; the vice-president Gore was in charge of leading the industrial innovation plan directly. The Management Commission was established whose members were senior officers of the eight government departments, chairmen or vice general managers of the three biggest auto enterprises, and the chairman of USCAR (USA Car Association). (2) Technology platform. A technology platform which was called the Experts Commission of PNGA was established whose members consisted of the main senior technological experts from the eight government departments, USCAR, GM, Ford and Daimler -Chrysler. (3) Information platform. The partnership for new generation automobile also organized the Secretary Sectors. It took charge of collecting data, information, books, and other useful materials and tackled them. At the same time, they took the role of a medium organization to broadcast the information coming from government. It was an efficient information platform.

(2) The industrial platform of partnership for new generation automobile. The industrial platform was in charge of promoting, supervising and stimulating research \& development activities. They identified the requirements in competitive fields and organized members to make breakthroughs of basic common technologies. (1) Management platform. USCAR oneself is a management platform that took charge of promoting, supervising and advancing per-competition fields' research and exploitation activities. (2) Technology platform. The USCAR moderated with industrial members effectively and broadly so as to ascertain the target of the project, and then established strategies. Hence the technology resources from government, enterprises and society were integrated to be an efficient technology platform. (3) Information platform. The Information Management Department of USCAR took charge of the role of information platform.

( 3 ) The enterprise platform of partnership for new 
generation automobile. During the operating process of partnership for new generation automobile, each of the three major enterprises (General Motors, Ford, or Daimler-Chrysler) established their own industrial strategic alliance, and actually the enterprise platform based on the core enterprise's product innovation platform was established. For example, taking Ford as the core enterprise, the new generation car "Prodigy" exploitation alliance was established and the sample car of "Prodigy" has already been manufactured.

\section{CONCLUSION}

Industrial innovation is a combinative innovation of technological innovation and institutional innovation. To implement an automobile industrial innovation activity, government, enterprises, universities, institutes and so on must cooperate with each other. By combining with government and social organizations, enterprises' product innovation platforms expand to be automobile industrial innovation platform.

According to the different function that the elements take, an automobile industrial innovation platform may be dividend into three layers of subsystems of public platform, automobile industrial platform and enterprise platform. Each of the three layers of an automobile industrial innovation platform consists of three sub-platforms of management platform, technology platform and information platform. The construction of an automobile industrial innovation platform should obey the principles of strategic object directing direction, plan mechanism combining with market mechanism, guiding by government combining with enterprises' corpus standing, social benefit combining with economic benefit principle. When an automobile industrial innovation platform has fulfilled its object, it will disappear or update according to updating mechanism. The result of the demonstration study authenticated the accuracy and the function of our theory study.

\section{REFERENCES}

[1] WU Qiang. Per-condition, Bottleneck and Breaking-through of Construction of National Value Chain under Two-side Market. [J] China Industrial Economics. 2010（3）. P25-29. (in Chinese)

[2] Han Min. Research on ASP Based Collaborative Modes, Techniques and Platform of Automotive Industry Chain. [D] Southwest Jiaotong University. 2006. (in Chinese)

[3] $\mathrm{Hu}$ Shu-hua, Guan Shun-feng, Wang Xiu-ting, National Innovation Strategy, Economic Management Press, 2003, p.76-80(in Chinese)

[4] Guan Shun-feng, Hu shu-hua, Research on Industrial Innovation Organization, [C] the Fourth Wuhan International Conference on E-Business, Wuhan, China, June 4-5,2005, p.1103-1108(in Chinese)

[5] XUE Jie. The Analysis of the Foreign Countries Experiences on the Construction of Generic Technology Platform and the Inspiration to the Platform's Construction in China. [J] Science of Science and Management of S.\& T.,2006(12) P125-128. (in Chinese)

[6] TU Jian-fei. The Technology Innovation Platform of Mould Industrial Clusters Based on the Innovation Chain. [J] China Soft Science, 2009(05) P57-61. (in Chinese)

[7] Zhuang Yue, Modern Integrated Principle and Method of Enterprise's Products Innovation, [J] Scientific Research Managing, 2002(1). P33-36. (in Chinese)

[8] LI Ping. Study on the Construction Model of Generic Technology Platform for Traditional Industry. [J] Studies in Dialectics of Nature, 2007(09) P61-64. (in Chinese)

[9] Robert son D. and Ulrich K., Planning for Product Platform, [J] Sloan Management Review, 2008, 39(4), p.19-31

[10] Mark Dodgson, and Roy Rothwell, Chen Jing[Translate], Industrial Innovation Manual [M]. Tsinhua university press, 2000 ( in Chinese) 